\title{
"Mas dry não é seco em inglês?" $O$ efeito de evidência de sentido para o sujeito entre línguas materna e estrangeira
}

Giovani Forgiarini Ainb*

Resumo: Filiado à Análise do Discurso de linha francesa, este artigo apresenta uma breve reflexão sobre os conflitos pelos quais passa um sujeito envolvido no processo de aprendizagem de uma língua estrangeira e, a partir disso, elucida tais conflitos com um episódio ocorrido em uma sala de aula de língua inglesa como língua estrangeira. Tal processo faz com que haja a possibilidade de uma reconfiguração identitária.

Palavras-chave: Língua materna; Língua estrangeira; Sentido.

Abstract: This paper is joined to French Discourse Analysis and presents a brief reflection on the conflicts in which a subject is involved when he is learning a foreign language, and this article also explains such conflicts through an incident occurred in a classroom of English as a foreign language. This process offers the possibility of a reconfiguration of identity.

Keywords: Mother tongue; Foreign language; Meaning.

Mestre em Letras, na área de Estudos da Linguagem, pelo PPG Letras/UFRGS. E-mail: gioaiub@gmail.com 


\section{Reflexões iniciais}

Quase sempre exigimos que a nossa própria linguagem prevaleça. Você tem que me entender mesmo que eu não o entenda - essa tem sido, ao longo dos séculos, a bandeira do colonizador (MANGUEL, 2008, p. 60).

Não é de se negar que quem aprende uma língua estrangeira tem a possibilidade de perceber outros modos de dizer, outras estruturas linguísticas, outros léxicos, outros sons, outras maneiras de se comunicar e também de não se comunicar. Além disso, quem aprende uma língua estrangeira tem a possibilidade de se deparar, em um primeiro momento, com o estranho (que vai se tornando familiar) e se deparar com o familiar (que vai se tornando passível de estranhamento). Aprender uma língua estrangeira é ainda deixar capturar-se, é imaginar que se domina, mas é ser tomado inconscientemente por esse outro da língua estrangeira (AIUB, 2008).

Entre estar tomado pela língua estrangeira e o desejo inicial de aprendê-la, estão os desentendimentos mais notórios, as falhas mais singelas, os questionamentos mais fortes, em suma, o complexo processo de aprendizagem. Neste ínterim repleto de novas formulações, hipóteses, lutas, embates, há a possibilidade de se perguntar por que eu digo assim?, em vez do olhar direcionado apenas para o outro (por que eles falam desse jeito?). Não se trata unicamente de mudar o ponto de vista. Trata-se de olhar para dentro, alterando o olhar sobre si mesmo, trata-se de se dar início a um processo de identificação. Processo este que, muitas vezes, não é teorizado, pois a concepção de sujeito que subjaz aos campos de ensino de línguas estrangeiras é de um sujeito cartesiano, plenamente consciente, um sujeito tomado como a origem e causa do dizer. Em muitas teorias sobre a linguagem, em especial as do ensino de línguas estrangeiras, não há lugar para reflexões sobre uma concepção de sujeito cindido, clivado, um sujeito assujeitado. Desse modo, tendo a premissa de que há o sujeito do discurso quando o indivíduo é interpelado pela 
ideologia (e ele sempre é), é relevante dizer que o processo de aprendizagem, seja ele qual for, não ocorre de maneira exclusivamente consciente.

Com o pressuposto de que o sujeito não é plenamente consciente e de que a língua não é transparente, este trabalho, partindo de um episódio ocorrido em sala de aula de língua inglesa como língua estrangeira, pretende mobilizar como a ilusão da transparência da língua vem à tona no processo de aprendizagem de uma língua estrangeira. Para isso, tomar-se-á como base os pressupostos teóricos da Análise do Discurso concebida por Michel Pêcheux, na França, e por Eni Orlandi, no Brasil, a saber, mais especificamente, as concepções de língua e de sujeito.

\section{Língua materna, língua estrangeira e reconfiguração identitária}

No ponto de vista aqui adotado, é preciso levar em conta que a língua não se resume a um conjunto de regras gramaticais, a estruturas sintáticas, a outros léxicos ou a novos fonemas. A língua é muito mais que isso, pois ela é estruturante do sujeito na medida em que o constitui, na medida em que é somente pela língua que o sujeito pode se fazer sujeito, ou seja, é somente submetendo-se à língua que se pode dizer/interpretar. Assim, quando se trata da aprendizagem de uma língua estrangeira, não é o sujeito que passa a dominar essa (nova) língua, pois jamais haverá domínio, no sentido de que é possível apropriar-se da língua, mas o que há é uma possibilidade de constituição subjetiva também por essa língua estrangeira, sendo que ela é a causadora de embates, de lutas, de confrontos internos à constituição subjetiva. Neste viés, cabe refletir como que o sujeito que está entre a língua materna e a língua estrangeira passa por estes embates, estes choques, estas colisões que o processo de aprendizagem pode causar, principalmente quando ele os materializa em sua escrita nesta outra língua. 
Nesta perspectiva, não se pode supor falar como apenas comunicar-se, pois "[...] falar é sempre um processo cuja complexidade estrutural supera o mero exercício de habilidades visando à 'comunicação' de mensagens ou à resolução de 'problemas' operacionais” (SERRANI-INFANTE, 1997, p. 65), de tal modo que aprender uma língua estrangeira é dar a possibilidade de uma luta intensa entre o que é familiar e o que é estranho, é abrir brechas para o distinto, o diferente, é dar-se conta de que há outros modos de dizer, outras formas de subjetivar-se, é dar lugar para a desconstrução da ilusão daquele mundo logicamente estabilizado pela língua materna. Ademais, "[...] aprender uma língua é sempre, um pouco, tornar-se outro" (REVUZ, 1998, p. 227).

Portanto, quando está em jogo a relação entre línguas materna e estrangeira, é preciso levar em conta que o sujeito, precisando necessariamente se inscrever em filiações sócio-históricas para que as palavras signifiquem, busca sentido nas palavras da língua estrangeira a partir de filiações já instaladas em sua constituição pela língua materna, o que pode causar falhas neste processo, já que a historicidade, que é a relação da linguagem com a história, não é idêntica na relação entre línguas. Assim, não há como pensar a língua estrangeira como se ela fosse apenas um conjunto de novas estruturas e novos léxicos.

Portanto, a língua estrangeira, assim como a língua materna, inscreve-se em filiações sócio-histórico-ideológicas, e é por esse caminho que se deve pensar a produção de sentidos em língua estrangeira. Não esquecendo, porém, que o sujeito já é estruturado pela língua materna e que esta, durante o processo de aprendizagem da língua estrangeira, insiste em afastar essa tal estrangeiridade. E aqui se pode fazer uma referência a Pêcheux (1990, p. 17), pois esta tentativa de afastamento da língua outra, que ocorre a partir deste cruzamento das línguas no sujeito, não deixa de poder ser vista também como "[...] pontos de resistência”. Essa é a luta

1 Pêcheux (1990, p. 17) aponta alguns exemplos de resistência quanto à dominação ideológica. Reproduzo aqui todos, mas chamo a atenção para os últimos. "As resistências: não entender o entender errado; não 'escutar' as ordens; não repetir as litanias ou repeti-las de modo errôneo, falar quando se exige silêncio; falar sua língua 
que todo sujeito vivencia quando o desejo de aprender uma outra língua permanece e se sobrepõe às tentativas da língua materna de expulsar o que é estranho.

Pensando a escrita, talvez não sejam tão raros os momentos nos quais, no processo de ensino de uma língua estrangeira, o professor se depare com uma escrita estranha, mesmo que em sua abordagem ele ofereça aos aprendizes modelos a serem seguidos a partir de estruturas linguísticas previamente estudadas e vocabulário previamente memorizado. $\mathrm{O}$ que se pressupõe aqui é que, no jogo professor-aluno, essa tal escrita estranha apresenta estranheza apenas para o professor, aquele que tem os conhecimentos necessários para acompanhar e apoiar o processo de aprendizagem de seus alunos e para poder verificar a maneira pela qual se dá a construção desta escrita. Além do mais, para quem escreve, para quem produz um texto em língua estrangeira, há necessariamente a ilusão de que aquilo que fora escrito produz evidências de um sentido já-lá.

O que se denomina aqui textos estranhos pode ser percebido por muitos professores como textos que carregam um grau muito alto de $\operatorname{erros}^{2}-$ algo comum se houver um aporte em bases teóricas

como uma língua estrangeira que se domina mal; mudar, desviar, alterar o sentido das palavras e das frases; tomar os enunciados ao pé da letra; deslocar as regras na sintaxe e desestruturar o léxico jogando com as palavras...”

2 Neste ponto, gostaria de dizer que não vejo diferenças profundas e consistentes entre o que a Linguística Aplicada (LA) considera erro e o que considera interlíngua. A interlíngua, teorizada por Selinker (1972, p. 214) é “" [...] a existência de um sistema linguístico separado baseado nas informações observáveis cujos resultados derivam das tentativas do aprendiz de produzir nas normas da língua alvo". Em outras palavras, pode ser entendida como uma transferência da língua materna para a língua estrangeira. Dito isto, apresento Martinez (2009, p. 55) que assevera que "[...] a contribuição da LA ao ensino de línguas se manifesta pelo interesse em uma abordagem diferencial ou contrastiva. Toma-se consciência de que os erros observados entre os aprendizes podem provir de diferenças entre as línguas primeira e segunda, logo, de transferências erradas tanto na codificação quanto na decodificação". A relação, portanto, entre línguas, vista sob a ótica da LA, é percebida, mas é trabalhada no viés do erro. $\mathrm{O}$ aprendiz erra quando ele faz relações entre as línguas que estão the constituindo: materna e estrangeira. De qualquer maneira, a tentativa de acabar com o erro produzido pelo aprendiz não cessa, mesmo que seja lhe dada uma outra nomenclatura. Para mais detalhes sobre essa discussão, ver trabalho já produzido anteriormente (AIUB, 2011). 
linguísticas. Nestes tipos de textos, existe a percepção de que eles não são escritos na língua estrangeira a qual se propunham estar, ou seja, mesmo que haja distintas palavras desta língua alvo, o que há por trás deste léxico e estruturas linguísticas alheios ao aluno é uma forte identificação deste com a língua materna. Apesar de esta identificação com a língua materna ser extremamente forte, ela apresenta poros por onde pode entrar o estranho da outra língua. E a entrada dessa estrangeiridade se dá aos poucos, pois, no momento da escrita em outra língua, é possível perceber a presença marcante da língua materna. Daí é que ocorre um significativo distanciamento do que é considerado correto na língua alvo ou, até certo ponto, aceitável gramaticamente.

Entretanto, é preciso levar em conta que o sujeito é constituído também de inconsciente e que, por isso, não está na sua alçada produzir textos nos quais a presença da língua materna não seja uma constante, isto é, não há como, pelo menos no início do processo de aprendizagem ou até que esta língua estrangeira capture este sujeito, criar textos sem que a regularidade da língua materna se projete em sua escrita e, dessa forma, se faça presente, a menos que sejam dadas estruturas linguísticas e palavras memorizadas para preencher um texto modelar.

Desse modo, o que o sujeito diz em língua materna não pode ser exatamente o mesmo em língua estrangeira, sobretudo porque a relação entre as línguas não é um jogo no qual há apenas uma troca lexical, não é tampouco um jogo no qual a estrutura linguística apenas inverte (ou entorta) os lugares sintáticos, não é também apenas alterações de ordem fonológica, mas é tudo isso juntamente com a percepção de que há outras formas de se colocar no processo discursivo. Dizer em língua estrangeira é sempre dizer de outra maneira. Portanto, a relação entre línguas é da ordem da desestabilização subjetiva, e esta desestabilização força o sujeito a uma reconfiguração identitária que tem como característica estar em constante movimento. Assim, esta relação entre língua materna e língua estrangeira é da ordem do embate, do choque, da colisão, pois as regularidades da língua materna, 
já impostas e enraizadas no sujeito, emergem a todo instante durante processo de aprendizagem da língua estrangeira. Neste viés, trata-se de uma reconfiguração identitária que não cessa, sobretudo porque ela não se finda. A reconfiguração identitária pode ser pensada como um abalo que o sujeito sofre ao entrar em contato com o estranho, com a estrangeiridade da língua estrangeira, mas não se trata de um abalo como um choque único, e sim de um abalo constante sobre as formas de ver um mundo previamente estabilizado pelo ilusório conforto da língua materna.

Nesta perspectiva, é preciso levar em conta que "[...] a questão da identificação como processo de subjetivação, por estar em constante construção, nunca é completado" (NEVES, 2006, p. 46). Porém, se assim fosse, haveria brechas para se pensar em um sujeito pleno, no sentido de idêntico à, no sentido de que seu ciclo identitário não se movimentaria e se encerraria em certo ponto. Nesta perspectiva, a reconfiguração identitária causada pelo contato com a língua estrangeira é da ordem de uma formação contínua, mas não linear. Esta reconfiguração se faz pelo contato com o outro e pelos conflitos que este contato causa. Conflitos estes que são constitutivos de toda e qualquer formação identitária, pois "[...] as identidades são formadas na relação inescapável e necessária com a alteridade" (GRIGOLETTO, 2006, p. 15).

A reconfiguração identitária, pensada a partir de outra língua, só existe, portanto, em função deste contato repleto de conflitos, lutas e embates com a alteridade. É a luta da língua materna (a língua do ilusório aconchego, do mundo estabilizado e da regularidade) para expulsar a língua estrangeira (a língua do desassossego, da desestabilização e da agitação). Estes conflitos, contudo, não são sanados por esta reconfiguração, uma vez que são constitutivos desta relação com o outro. Neste viés, cabe dizer que a reconfiguração identitária passa sempre pelo processo de identificação, pois assim como não há identificação plena, não há, da mesma forma, uma reconfiguração fechada, como se tivesse um ponto a ser alcançado. 


\section{O efeito de evidência de sentido entre línguas materna e estrangeira: um caso de historicidade e ideologia}

O efeito de evidência do sentido faz parecer como transparente aquilo que, numa remissão a outras formações discursivas $^{3}$, poderia produzir outros sentidos. Dito de outro modo, o sentido, mesmo sendo sempre em relação $a$, aparece ao sujeito como sendo somente aquele. Quanto ao efeito de evidência do sujeito, vale dizer que se trata de um apagamento do fato de que o indivíduo é interpelado em sujeito pela ideologia. Entende-se ideologia aqui não como um conjunto de representaçôes, nem como uma visão de mundo, menos ainda como uma ocultação da realidade, mas sim como

[...] uma prática significante que aparece como efeito da relação necessária do sujeito com a língua e com a história para que haja sentido. E como não há uma relação termo-a-termo entre linguagem/ pensamento/mundo, essa relação torna-se possível porque a ideologia intervém com seu modo de funcionamento imaginário (ORLANDI, 2005a, p. 48).

A ideologia aqui aparece como efeito da relação do sujeito com a língua e com a história. Ela não é ocultação, é uma prática significativa. O sujeito é, nesta perspectiva, lugar historicamente constituído de significação.

Desta forma, as palavras, enunciados, expressões, por sua vez, evidenciam que a língua nunca é aquilo que ela designa, mas sim uma representação, ou seja, a língua (e aqui se pode entender e afirmar que se trata da linguagem) é simbólica. Para Orlandi

3 Formação discursiva é " [...] aquilo que, numa formação ideológica dada, isto é, a partir de uma posição dada numa conjuntura dada, determinada pelo estado da luta de classes, determina o que pode e deve ser dito". Desse modo, vale salientar que os sentidos são dados dentro das formações discursivas. Logo, pode-se admitir que "[...] as mesmas palavras, expressões e preposições mudam de sentido ao passar de uma formação discursiva a uma outra”, ou seja, "a formação discursiva é o lugar da constituição dos sentidos” (PÊCHEUX, 2009, p. 146-147). 
(2009, p. 23), “[...] é o ‘acontecimento’ do objeto simbólico que nos afeta como sujeitos. Algo do mundo tem de ressoar 'no teatro da consciência' do sujeito para que faça sentido.” Sujeito e linguagem, por conseguinte, estão relacionados na medida em que o sujeito é constituído pela linguagem e a linguagem é um espaço de constituição dos sentidos. Sentidos estes que são sempre inscritos na história.

Ligada fortemente ao sujeito e ao sentido, está a noção de ideologia, já comentada anteriormente. É a ideologia, pois, a responsável pelo direcionamento dos sentidos; é ela que interpela o indivíduo em sujeito. Sendo, desta maneira, a determinante pelo efeito de evidência. Nas palavras de Ferreira (2003, p. 192), "[...] a ideologia ainda vai apontar para uma interpretação de sentido em certa direção, determinada pela relação da língua com a história $[\ldots]$ ", ou seja, ela trabalha na contradição que há entre a linguagem e o mundo.

A ideologia disfarça (dissimula) e faz com que não haja coincidência entre a essência e a aparência (ela é responsável por aquilo que aparenta ser sob determinada perspectiva). De acordo com Orlandi (2004, p. 66), "[...] a ideologia representa a saturação, o efeito de completude que, por sua vez, produz o efeito de 'evidência', sustentando-se sobre o já dito, os sentidos institucionalizados, admitidos por todos como 'naturais". É o trabalho da ideologia, por conseguinte, que torna o processo de constituição dos sentidos inacessível ao sujeito de tal modo que haja sempre interpretação. Em outras palavras,

[...] é pela interpretação que o sujeito se submete à ideologia, ao efeito de literalidade, à ilusão do conteúdo, à construção da evidência dos sentidos, à impressão do sentido já-lá. A ideologia se caracteriza assim pela fixação de um conteúdo, pela impressão do sentido literal, pelo apagamento da materialidade da linguagem e da história, pela estruturação ideológica da subjetividade (ORLANDI, 2005b, p. 22).

Assim, há sempre interpretação, pois não há sentido que não passe por um gesto interpretativo do sujeito. E a ideologia é o motor deste processo. Aí está mais uma evidência de que 
sujeito e sentido se constituem de forma mútua. Por isso que, ao se produzir um sentido tal (ao dizer), interpreta-se, pois a interpretação pode ser vista como uma significação, um gesto de leitura de um determinado fato. Diante do movimento de interpretação, o sentido aparece sempre como evidente. Há, portanto, o trabalho da ideologia sobre o gesto interpretativo, como se o sentido, produzido na relação do simbólico com o histórico, fosse naturalizado. Daí afirmar que o sentido aparece como sempre já lá. Orlandi (2005a, p. 46) diz que "[...] por este mecanismo - ideológico - de apagamento da interpretação, há transposição de formas materiais em outras, construindo-se transparências [...]. Este é o trabalho da ideologia: produzir evidências". Deste modo, interpretar não pode ser percebido como um mero gesto de decodificação, pois, ao interpretar, há uma exposição inevitável à incompletude do objeto simbólico, ou seja, não se tem nunca acesso ao todo, embora haja o desejo de tal e a ilusão de tal. Ainda com Orlandi (2005a, p. 45), "[...] não há sentido sem interpretação e, além disso, diante de qualquer objeto simbólico o homem é levado a interpretar”. Assim, interpretar não é apenas dizer o esperado, trata-se de fazer relação com a exterioridade, pois "[...] a interpretação não é mero gesto de decodificação, de apreensão do sentido. Também não é livre de determinações. Ela não pode ser qualquer uma e também não é igualmente distribuída na formação social" (ORLANDI, 2004, p. 67).

A partir do exposto, pode-se perceber que a interpretação está intimamente ligada à ideologia. E esta, por sua vez, é a responsável por direcionar os sentidos, pelo efeito de evidência. A ideologia também assume outro papel importante quando pensada em relação ao sujeito: é ela que faz com que o indivíduo se torne o sujeito do discurso, uma vez que o indivíduo só se coloca na posição de sujeito quando é interpelado pela ideologia. Entretanto, há de se mencionar também que não há maneira de escapar da interpelação ideológica, pois todo indivíduo só pode ser agente de práticas sociais quando se reveste da forma-sujeito, 
que é a forma da existência histórica. Então, quando a ideologia interpela o indivíduo, há o sujeito do discurso (ORLANDI, 2006). Portanto, quando se fala em sujeito, não se está tratando de um sujeito psicológico, empírico, consciente, centrado, cartesiano, livre, controlador do que diz, mas de um sujeito assujeitado, fragmentado, cindido, um sujeito que se constitui na e pela linguagem e, sendo constituído dessa forma, não pode ser pensado como completo, pleno, absoluto, indissolúvel, mas sim um sujeito que é sujeito à língua. E, sendo condicionado à língua, outra de suas características diz respeito à incompletude. O sujeito discursivo nunca é completo, embora esta seja sua marca: a busca incessante por uma completude inatingível. Desta maneira, é possível afirmar que a existência de um sujeito desejante é constante. Para corroborar com o que vem sendo dito até agora, Orlandi (2005a, p. 20) afirma que

[...] o sujeito de linguagem é descentrado, pois é afetado pelo real da língua e também pelo real da história, não tendo o controle sobre o modo como elas o afetam. Isso redunda em dizer que o sujeito discursivo funciona pelo inconsciente e pela ideologia.

Dito de outra forma, o sujeito não é dono do dizer, pois é afetado pelo inconsciente e não domina os sentidos, uma vez que é interpelado ideologicamente, ou seja, o sujeito é duplamente afetado. Não há, portanto, sujeito livre. Ele é interpelado pela ideologia e, consequentemente, filiado a uma formação discursiva, ocupando, dentro dela, uma posição-sujeito. E essa posição que o sujeito ocupa, na instância discursiva, que é responsável pela atribuição de sentidos, não dos possíveis sentidos, mas da evidência de dado sentido em determinada posição inscrita em determinada formação discursiva. A partir disso, pode-se dizer que, sendo o sujeito constituído pela linguagem, pois é ela que o estrutura, em uma estruturação recheada de falhas, e, sendo o sujeito interpelado pela ideologia, ele, que ocupa um lugar na camada social, sofre diversas determinações. Por isso, precisa se render às condiçôes que a língua impõe para poder dizer. Para Ferreira (2007, p. 101), "[...] falar do sujeito, é falar, de algum 
modo, da falta que lhe é inerente e que o constitui”. Essa falta, por sua vez, é o que faz com que se abram as possibilidades de diferentes sentidos, de rupturas, de falhas. Ainda com a mesma autora, pode-se afirmar que "[...] se não houvesse a falta, se o sujeito fosse pleno, se a língua fosse estável e fechada, se o discurso fosse homogêneo e completo, não haveria espaço por onde $\mathrm{o}$ sentido transbordar, deslizar, desviar, ficar à deriva" (FERREIRA, 2004, p. 40). E é neste espaço que a Análise do Discurso trabalha, no lugar onde sentido e sujeito não são absolutos.

Não sendo pleno, nem controlador do seu dizer, mas tendo esta impressão, o sujeito, afirma Pêcheux (2009, p. 150), "[...] constitui-se pelo 'esquecimento' daquilo que o determina”. Em outras palavras, o sujeito ignora outros sentidos possíveis, provenientes de outras formações discursivas e tem a ilusão de que é a fonte do dizer e a ilusão de controlar o que diz. Para Indursky (2000, p. 70), “[...] o sujeito da Análise do Discurso não é só social, mas também é dotado de inconsciente, o que faz com que o sujeito atue sob o efeito de duas ilusões: pensa ser a fonte do seu dizer e ser responsável pelo que diz.”

Deste modo, o sujeito está ligado a dois tipos de esquecimento, os quais Pêcheux e Fuchs (1997, p. 176) denominaram "[...] esquecimento $\mathrm{n}^{\mathrm{o}} 1[\ldots] " \mathrm{e}$ "[...] esquecimento $\mathrm{n}^{\mathrm{o}} 2[\ldots]$ ". $\mathrm{O}$ esquecimento $\mathrm{n}^{\mathrm{o}} 1$ trata de uma realidade discursiva ilusória. É uma zona inacessível ao sujeito e, por isso, este esquecimento é visto como constitutivo da subjetividade na língua. Trata-se, portanto, de um recalque de natureza inconsciente, na medida em que a ideologia não é acessível ao sujeito. Assim, o sujeito tem a ilusão de estar na fonte do sentido, ele acredita ser a fonte de seu discurso, pensa ser o criador do que diz e ignora os sentidos que se remetem a outras formações discursivas. Este esquecimento refere-se às condições de existência da relação subjetiva, isto é, refere-se ao não-formulável, ao não-afirmado e é ele que regula a relação entre o dito e o não-dito.

Já no esquecimento $\mathrm{n}^{\mathrm{O}} 2$, o sujeito tem a ilusão, ao retomar o que disse, de que sabe e controla o dizer e de que o dito tem 
apenas uma interpretação, um significado que é captado pelo seu interlocutor. No campo do esquecimento $\mathrm{n}^{\mathrm{O}} 2$, está a fonte da impressão de realidade do pensamento (eu tenho consciência do que eu falo). É o lugar para explicar a si próprio o que disse, para

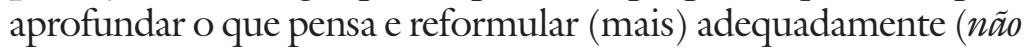
era bem isso o que eu quis dizer). O sujeito adentra conscientemente na zona do esquecimento $\mathrm{n}^{\circ} 2$, isto pelo retorno de seu discurso (o do sujeito) sobre si, ou seja, uma antecipação ao/do efeito do (seu) discurso. Aqui está o campo das estratégias discursivas, tais como a interrogação retórica, a reformulação tendenciosa e o uso manipulatório da ambiguidade. Assim, este esquecimento $\mathrm{n}^{\mathrm{o}} 2$ é marcado por um funcionamento do tipo pré-consciente/ consciente, no qual estão os processos de enunciação. E é neste processo que há um espaço para que o sujeito tenha a ilusão do acesso ao sentido, como se ele fosse único.

Com relação ao processo de produção escrita ou oral em uma língua estrangeira, são geralmente comuns algumas reformulações feitas pelo sujeito na posição de aprendiz desta outra língua ${ }^{4}$. Ao mesmo tempo, também se nota que para o sujeitoaprendiz há a ilusão de existir um único sentido para dada produção. Isto é, ao dizer dada palavra, frase, proposição, expressão, etc. em língua estrangeira, há o imaginário de que seu funcionamento é idêntico ao da língua materna. Como o movimento entre as (ou das) línguas não é idêntico, ocorre o equívoco. O equívoco, neste caso, não só é da ordem de formação discursiva (lugar de constituição dos sentidos), mas principalmente de ordens sociais distintas, de historicidades distintas, uma vez que uma língua não é idêntica à outra. Assim como não existe uma relação direta entre as coisas do mundo e a linguagem, isto tampouco ocorre entre distintas línguas. $\mathrm{O}$ sujeito-aprendiz, ao fazer uma relação direta entre sua língua e a estrangeira, tem a impressão de que o sentido é a-histórico e de que ele é a única fonte deste saber.

4 Daqui em diante, quando o sujeito estiver na posição de aprendiz, usar-se-á o termo sujeito-aprendiz, diferenciando-o, assim, do sujeito empírico e remetendo-o ao sujeito do discurso. 


\section{Do episódio na sala de aula da estrangeira língua inglesa}

Para elucidar esta relação entre línguas materna e estrangeira, os sentidos e o sujeito na posição de aprendiz, vale relembrar um episódio ocorrido em sala de aula. Trata-se de uma experiência ímpar da qual pude fazer parte. $\mathrm{O}$ protagonista era um aluno da quinta série do Ensino Fundamental de uma escola pública da região metropolitana de Porto Alegre/RS. Resumidamente, afirmo que este episódio, ocorrido em 2005, provém de minha prática docente e foi um dos motes que me impulsionou a não seguir os estudos sobre língua estrangeira pelo viés da Linguística Aplicada ${ }^{5}$, mas sim pelo da Análise do Discurso. Nas linhas abaixo, o tal acontecimento (AIUB, 2011).

Como professor, responsável pelas aulas de Língua Inglesa de uma turma de quinta série do Ensino Fundamental, havia solicitado uma tarefa cujos objetivos eram contrastar alguns adjetivos da língua inglesa e, logo depois, desenhar, em um pequeno cartão de cartolina, algo que representasse os tais adjetivos. Lembro de ter escrito no quadro-negro uma lista de adjetivos, em língua inglesa, tais como short/tall, big/small, strong/weak, heavy/light, thin/fat, etc., e ainda $d r y /$ wet $^{6}$. Esta era a rudimentar fonte dos alunos, além de um dicionário bilíngue.

A época, não percebia o quão descontextualizada e ingênua era a tarefa, pois, imaginariamente, o único lugar para a produ-

5 A título de curiosidade, gostaria de relatar que, no ano de 2005, eu, estudante do curso de Letras e professor de escolas da rede pública do Estado do RS, fazia parte do Núcleo de Apoio Pedagógico da UFRGS (NAP/RS), que à época era coordenado pela Prof ${ }^{a}$ Me. Jussara Maria Zilles. Este núcleo, a partir de pesquisas calcadas na Linguística Aplicada, promovia diversas atividades pedagógicas de extensão a fim de auxiliar na prática docente de professores e de futuros professores de língua estrangeira. O NAP esteve em atividade desde maio de 1988 até início de 2008, estando, atualmente, desativado. Para saber mais sobre o NAP, acessar http://www6.ufrgs. br/iletras/nap/index.htm.

6 Segue uma possível tradução para estas palavras respectivamente: baixo/alto, grande/ pequeno, forte/fraco, pesado/leve, magro/gordo e seco/molbado; porém, é importante ressaltar que as possibilidades de se encontrar palavras outras não se encerram. 
ção de sentidos estaria na língua sistêmica por e com ela mesma, ou seja, pela oposição entre elementos linguísticos distintos. Neste ponto, é possível relembrar Saussure (2006, p. 136), pois "[...] quando se diz que os valores correspondem a conceitos, subentende-se que são puramente diferenciais, definidos não positivamente por seu conteúdo, mas negativamente por suas relações com outros termos do sistema." Foi exatamente o que eu havia feito com os pares de adjetivos em língua estrangeira: uma tentativa de conceitualização/tradução por oposição, não por todos os termos do sistema, mas por pelo menos alguns deles $^{7}$. Pensando deste modo, não poderia haver possibilidade de equívoco, não poderia haver a possibilidade de escapar outros sentidos, de deslize. Mas não foi o que ocorreu.

Depois de os alunos, grande parte deles pelo menos, terem buscado o significado no dicionário das palavras em inglês e terem desenhado uma representação de cada um dos adjetivos, um aluno me chamou muito a atenção, pois ele havia rabiscado algo que achei notável. Para a palavra $d r y$, este aluno, diferentemente de seus colegas, tinha desenhado a imagem de uma pessoa muito magra. Então, lhe perguntei o que desenhara. Logo, ele me dissera que estava fazendo o desenho de $d r y$, pois havia já estruturado a imagem da seguinte sequência discursiva: he is dry, que foi relacionada com ele é seco e não com ele está seco. Naquele momento, ainda não conhecedor das teorias discursivas, disse a ele que estava errado, pois o desenho caberia melhor na palavra thin. Foi então que a sua pergunta, extremamente intrigante, se fez: “'mas dry não é 'seco' em inglês?!, pois é, estou desenhando um 'cara' seco." Como poderia eu continuar afirmando que ele ainda havia errado? O que fez aquele aprendiz interpretar 'seco' não

$7 \quad$ Vale deixar registrado aqui que Saussure não mobiliza a questão do referente quando trata da instituição da Linguística como ciência. O interesse primordial de Saussure é descrever o funcionamento da língua enquanto sistema, não interessando a referencialidade. Isto passa a ser, mais tarde, uma preocupação de Benveniste (2005, p. 279), quando este autor analisa os pronomes de pares reversíveis. Em suas palavras, “a forma 'eu' só tem existência linguística no ato de palavras que a profere. Há, pois, neste processo uma dupla instância conjugada: instância do 'eu' como referente, e instância do discurso contendo 'eu', como referido". 
como oposto de 'molhado', mas (talvez) de 'gordo’? É possível dizer que, se tomado o episódio pelo viés da linguística (aplicada), essa problematização se resumiria a dizer que foi um erro do indivíduo. Em AD, contudo, não é possível pensar na concepção de erro, pois isto leva a crer que há um sujeito consciente, controlador do dizer, que é passível de acerto e, por conseguinte, também de erros. Quando se percebe o sujeito dividido, clivado, há necessariamente de se pensar em equívoco, não em erro, pois o dizer não advém de um controle pleno. No máximo, o que pode haver é o jogo das estratégias pensado por Pêcheux e Fuchs (1997) quando tratam do esquecimento $\mathrm{n}^{\mathrm{O}} 2$.

Sobre este ponto, é importante ressaltar que é a ideologia a fornecedora de evidências que fazem um dado enunciado parecer significar o que ele (não) significa. Isto é, estas evidências mascaram o sentido ao se valerem do efeito da transparência da linguagem.

Ainda em relação ao episódio de sala de aula, o efeito da transparência da língua(gem) surge de ambos os lados, tanto por parte do professor, imaginando que haveria apenas uma única interpretação para $d r y$, ou em língua materna, imaginando que seco só poderia ser seco, tal como a concepção de uma língua homogênea; quanto por parte do aprendiz, que, ao traduzir tal vocábulo, aplicou-lhe a historicização da língua materna, e esta, quando levada para a língua estrangeira, faz com que o sentido produzido não seja mais o mesmo, ou seja, seco passa a ser um indivíduo magro ${ }^{8}$.

Evidencia-se, a partir daí, que o sujeito-aprendiz estava fortemente identificado com a língua materna, ademais com uma variedade não-padrão da língua, pois seco significou, para ele, algo diferente do sentido mais regular, estando na ordem de um efeito metafórico, e estes sentidos, em uma concepção de língua transparente, escapam.

\footnotetext{
8 É possível afirmar ainda que esta palavra, em outras condições, pode derivar seu sentido, como, por exemplo, em relação às frutas, no qual o sentido poderia ser murcho, sem seiva; e, em relação à meteorologia, não-úmido, sem chuvas, entre outros.
} 
Por este singelo acontecimento de sala de aula, pode-se perceber a incompletude do sujeito, pois o dizer não é controlável, muito menos são controláveis os desvios que as atividades de sala de aula podem proporcionar.

Pela vivência deste episódio, ainda foi interessante constatar como a língua é passível de rupturas, de falhas e de brechas por onde outros sentidos podem transbordar. Além disso, lidar com algo novo (e aqui entra o novo pela estrangeiridade) é algo que custa ao sujeito. Um aceite do novo acaba por incomodar o velho, o velho da língua materna que já estrutura o sujeito. Este velho da língua primeira é o aconchego do lar, o lugar do repouso, do residir tranquilo, que acaba sendo abalado por este forasteiro estranho. Mas esse incômodo faz com que se instaure outras percepções, outros modos de dizer, faz com que o sujeito exercite outros olhares, olhares para a diversidade. Para corroborar, Revuz (1998, p. 215) afirma que

[...] este estar-já-aí da primeira língua é um dado ineludível, mas essa língua é tão onipresente na vida do sujeito, que se tem o sentimento de jamais tê-la aprendido, e o encontro com uma outra língua aparece efetivamente como um experiência totalmente nova. A novidade, entretanto, não está no encontro com o fenômeno linguístico como tal, mas nas modalidades desse encontro.

Pensando ainda no episódio, o qual deve ocorrer de diferentes maneiras em distintas aulas de línguas, é de se questionar por que ainda não se mobiliza a exterioridade linguística quando o processo de aprendizagem de línguas (estrangeiras) está em jogo. Talvez seja esta uma das justificativas para que Revuz (1998, p. 213) afirme que "[...] a aprendizagem de línguas 'estrangeiras' se destaca principalmente pela sua taxa de insucesso".

Ao contrário de uma abordagem linguística e psicológica no processo de aprendizagem de línguas, é ancorando-se na $\mathrm{AD}$ que se podem mobilizar outras explicações para a situação ilustrada, e não apenas dizer que se trata de um erro. Em uma abordagem discursiva, há a mobilização do efeito de sentido entre interlocutores, por este motivo é que “[...] não é possível pensar 
na transmissão de informação entre interlocutores. Pensar nestes termos conduz a uma concepção de sentido prévio, estabilizado, verdadeiro, único, sem lugar para a ambiguidade, para o desvio e para o mal-entendido" (INDURSKY, 1998, p. 12).

Neste viés, é que se pode dizer que a língua não é transparente, ela se caracteriza pela sua opacidade, pelos seus furos, justamente porque "[...] todo enunciado é intrinsecamente suscetível de tornar-se outro, diferente de si mesmo, de deslocar discursivamente de seu sentido para derivar para um outro" (PÊCHEUX, 2006, p. 53).

Ainda sobre o episódio ocorrido comigo e com o meu aluno, eu, como sujeito marcado fortemente por uma concepção de língua fechada em si mesma e homogênea, não previ um espaço para o desentendimento, para um deslizamento de sentido, pois, como afirma Ferreira (2000, p. 21),

[...] é frequente se operar com uma elisão no caráter material da língua.

O sentido das palavras, dos enunciados, das proposições aparece como se já estivesse dado, cabendo ao sujeito reconhecê-lo e adequá-lo ao seu dizer. Cria-se, assim, a ilusão de um sentido desprovido de história e de um sujeito como origem de si próprio.

Como se pôde perceber, esta atividade de ensino que mobilizou uma concepção de língua sistêmica não funcionou muito bem para um de meus alunos. Além disso, penso que, para os outros, esta tarefa também não foi tão significativa. Esta mobilização da língua fechada em si mesma é, como afirmou Ferreira (2000), frequente. No ocorrido, houve uma tentativa de trabalhar como se o sujeito fosse desprovido de história e que o sentido se desse somente em relação a outros termos do sistema. Esta foi uma tentativa de ensino de língua estrangeira, como se viu, frustrada.

No que diz respeito à escrita em língua estrangeira, quando há um sujeito-aprendiz tendo seus primeiros contatos com esta outra língua, é comum, nas abordagens de ensino, haver uma escrita calcada em estruturas prévias, ou seja, não tendo espaço para que o sujeito possa se colocar, deslizando os sentidos. A 
escrita, por sua vez, não deve ser pensada por este viés, pois se trata de um gesto de interpretação e, como toda interpretação, requer um posicionamento. Este posicionamento também pode ser feito pela submissão a uma língua estrangeira. Desta forma, é possível dizer que, ao escrever em uma língua estrangeira, o sujeito se submete à língua, mas essa submissão é passível de falhas, pois há um embate, uma constante luta interior, uma vez que a língua materna tende a se fazer presente, seja pela sua estrutura linguística, seja por redes de filiações sócio-históricas distintas da língua estrangeira. Por isso afirmar que

[...] o sujeito precisa inscrever-se em processos identificatórios nessa língua [estrangeira] e, portanto, acaba por realizar movimentos que coloquem em jogo um outro imaginário, já que a produção de sentidos não ocorre no vazio. Esse imaginário [...] tem uma função de sustentação da identificação para a formação da identidade, e só por um trabalho de desarranjo/rearranjo da forma-sujeito [...] essa identidade pode estar sempre em formação/transformação, possibilitando ao sujeito o encontro com outros lugares de dizer (NARDI, 2005, p. 162).

Deste modo, é possível afirmar que o motor da aprendizagem é o desejo. E este desejo está fortemente ligado ao encontro com estes outros lugares de dizer, ligado à vontade de se ter a tal liberdade (ilusória) de escolha de dizer ora em uma língua ora em outra. No entanto, vale a ressalva de que o sujeito não está livre das filiações às quais as línguas estão inscritas e, tendo ele de se submeter à língua, estas filiações acabam inevitavelmente causando, mais cedo ou mais tarde, este desarranjo/rearranjo no processo de identificação do sujeito.

Voltando ao episódio de meu aluno, algo semelhante, porém fora do ambiente de sala de aula, ocorreu com a professora e pesquisadora argentina Maria Teresa Celada. Vinda da Argentina sem ter estudado português, ela conta seu equívoco da seguinte maneira:

[...] cheguei ao Brasil sem ter estudado português e, para ser entendida, falava espanhol devagarinho e o 'mais claro' possível, até que, aos poucos, surpreendi-me ensaiando alguns fragmentos da nova língua [...]. Certo dia, eu estava no balcão [de atendimento da secretaria do 
Departamento de Linguística da UNICAMP] e, mesmo havendo no local vários funcionários, todos pareciam ocupados e ninguém disposto a me atender, fato que me levou a tomar a iniciativa de perguntar, em 'meu melhor português': 'escuta, não tem nenhum empregado que possa me atender?’ (CELADA, 1999, p. 303).

Já por estas palavras, é possível perceber que o vocábulo “empregado" utilizado por Celada (1999, p. 303) não soou muito bem aos ouvidos dos funcionários da tal secretaria. Na tentativa de usar uma aproximação com a palavra em espanhol empleado, Celada comete o que se pode chamar de um equívoco, pois "sua intenção" (vale dizer que não há como controlar intenções) não era a de cometer tal mancada, como ela mesma fala (CELADA, 1999, p. 304). Pensando, então, que as línguas não têm a mesma história, não tendo, portanto, representações idênticas, Celada (1999, p. 307) afirma que, neste caso (mas é possível imaginá-lo como uma ilustração, pois casos como este ocorrem de diferentes maneiras, em distintos momentos), o que entrou em cena foi "[...] um gesto habitual do aprendiz de língua estrangeira: aquele pelo qual ele traduz palavra por palavra da frase, por efeito do imaginário que o leva a acreditar que ter acesso a uma língua é ter acesso às palavras".

Voltando ao episódio ocorrido em sala de aula, o aluno, com acesso às palavras, aplicou-as de acordo com a sua identificação com a língua materna. Ele operou, portanto, com o imaginário de que as línguas, tanto materna quanto estrangeira, funcionam igualmente, têm a mesma história e que seus modos de dizer são exatamente os mesmos. Nos casos aqui apresentados, pôde-se perceber que as línguas funcionam diferentemente e que causam no sujeito um desconforto, isto é, o processo de vivência de uma língua estrangeira, seja em sala de aula, seja num ambiente em imersão, causa uma desestabilização no mundo logicamente organizado pela língua materna. É nesta perspectiva que se pode dizer que o processo de aprendizagem de uma língua estrangeira é o que pode fazer com que o sujeito olhe para si e se questione: que outras formas de dizer há além daquelas que eu 
estou familiarizado? Por isso a importância do ensino de línguas estrangeiras no ambiente escolar, uma vez que nem todos têm a oportunidade de vivenciar este processo em uma situação, que se pode dizer, mais ampla.

\section{Considerações finais}

Para concluir, vale dizer que evitar a alteridade no processo de ensino de uma língua estrangeira apenas faz com que se mantenham concepções de língua homogênea e de sujeito consciente. Com uma concepção de língua homogênea, não há a possibilidade de se pensar em efeitos de sentido, pois o sentido seria sempre apenas um, e com a noção de um sujeito pleno, há a ideia de que ele é capaz de seguir o que lhe é ensinado sem que haja possibilidades de equívocos.

Dito isto, vale retomar o conceito de historicidade e afirmar que este trata da relação que a língua faz com a história e como esta relação produz sentidos. Em outras palavras, " [...] como os significantes não estão soltos, eles se realizam na historicidade e se espacializam na medida em que se coloca o discurso em texto" (ORLANDI, 2005b, p. 94). Assim sendo, cabe ressaltar que cada língua tem a sua relação específica com a história e que, por isso, cada uma tem a sua historicidade que são, geralmente, de ordens distintas, podendo, de vez em quando, ser semelhantes.

Ainda com relação à aprendizagem de uma língua estrangeira, pode-se dizer que a estrangeiridade que a acompanha pode causar no sujeito uma desestabilização que vem na ordem de questionamentos. E é por estes questionamentos que há a possibilidade de uma reconfiguração subjetiva, pois o contato com a língua estrangeira, mesmo que este contato seja restrito ao ambiente escolar, faz com que haja a percepção de outras formas de dizer, de outros sentidos ocultados pela forte e íntima relação que o sujeito tem com a língua materna, com a língua que o estrutura. Nesta perspectiva, não se pode mobilizar o ensino de 
uma língua estrangeira (ou não) apenas por um viés linguístico. É preciso dar aos aprendizes a possibilidade de posicionamento, de uma inscrição nestas novas formas de dizer. Não se pode ter a ideia de que a língua é formada apenas por estruturas linguísticas e léxicos distintos, pois isto nada mais é do que uma ilusão. Esta ilusão, portanto, não poderia fazer parte dos processos de ensino e de aprendizagem de uma outra língua. É necessário um trabalho com a língua estrangeira que dê condiçôes para que entre em jogo a historicidade, para que seja tomado o equívoco como constitutivo do processo de aprendizagem, justamente porque " $[. .$.$] a linguagem nunca é inocente: as palavras têm uma$ memória segunda que se prolonga misteriosamente no meio das significações novas” (BARTHES, 2004, p. 15). Desse modo, o ensino de línguas estrangeiras deve se pautar nesta presença outra, na presença da alteridade que se faz constante no contato com estas línguas estranhas.

\section{Referências}

AIUB, Giovani Forgiarini. Entre uma língua e outra, entre o materno e o estranho: lugar de interferências, historicidades e reverberações. 2011. 176f. Dissertação (Mestrado em Letras). Porto Alegre: Instituto de Letras/ UFRGS, 2011.

AIUB, Giovani Forgiarini. A imagem sobre o ensino de língua inglesa na escola pública: um repetível genérico. Cadernos do IL (UFRGS), Porto Alegre, v. 1, n. 36, p. 111-125, jun/2008. Disponível em: <http:// seer.ufrgs.br/cadernosdoil/article/view/18918/11016> Acesso em: 27 abr. 2011.

BARTHES, Roland. O grau zero da escrita: seguido de novos ensaios críticos. Tradução de Mario Laranjeira. 2. ed. São Paulo: Martins Fontes, 2004.

BENVENISTE, Émile. Problemas de linguística geral I. 5. ed. Tradução de Maria da Glória Novak e Maria Luisa Neri. Campinas: Pontes, 2005. 
CELADA, Maria Teresa. Um equívoco histórico. In: INDURSKY, Freda; FERREIRA, Maria Cristina Leandro. (Orgs.). Os múltiplos territórios da Análise do Discurso. Porto Alegre: Sagra Luzzatto, 1999, p. 301-320.

FERREIRA, Maria Cristina Leandro. A trama enfática do sujeito. In: INDURSKY, Freda; FERREIRA, Maria Cristina Leandro. (Orgs.). Análise do Discurso no Brasil: mapeando conceitos, confrontando limites. São Carlos: Claraluz, 2007, p. 101-108.

FERREIRA, Maria Cristina Leandro. Análise de Discurso e Psicanálise: uma estranha intimidade. Correio da APPOA. Porto Alegre, n. 131, p. 37-52, dez. 2004.

FERREIRA, Maria Cristina Leandro. O caráter singular da língua no discurso. Organon: discurso, língua e memória, Porto Alegre, v. 17, n. 35. p. 189-200, 2003.

FERREIRA, Maria Cristina Leandro. Da ambiguidade ao equívoco: a resistência da língua nos limites da sintaxe e do discurso. Porto Alegre: Ed. da UFRGS, 2000.

GRIGOLETO, Marisa. Leituras sobre a identidade: contingência, negatividade e invenção. In: MAGALHÃES, Izabel; GRIGOLETO, Marisa; CORACINI, Maria José. (Orgs.). Práticas identitárias: língua e discurso. São Carlos: Claraluz, 2006, p. 15-26.

INDURSKY, Freda. A fragmentação do sujeito em Análise do Discurso. In: INDURSKY, Freda; CAMPOS, Maria do Carmo. (Orgs.). Discurso, memória, identidade. Porto Alegre: Sagra Luzzato, 2000, p. 70-81.

INDURSKY, Freda. A Análise do Discurso e sua inserção no campo dos estudos da linguagem. Cadernos do Instituto de Letras (UFRGS), Porto Alegre, n. 20, p. 7-21, dez. 1998.

MANGUEL, Alberto. A cidade das palavras: as histórias que contamos para saber quem somos. Tradução de Samuel Titan Jr. São Paulo: Cia. das Letras, 2008.

MARTINEZ, Pierre. Didática de línguas estrangeiras. Tradução de Marco Marcionilo. São Paulo: Parábola Editorial, 2009.

NARDI, Fabiele Stockmans de. Identidade, memória e os modos de subjetivação. In: INDURKY, Freda; FERREIRA, Maria Cristina Leandro. 
(Orgs.). Michel Pêcheux e a Análise do Discurso: uma relação de nunca acabar. São Carlos: Claraluz, 2005, p. 157-166.

NEVES, Marialice de Souza. O processo identificatório na relação professor-aluno na aprendizagem de língua estrangeira. In: MAGALHÃES, Izabel; GRIGOLETTO, Marisa; CORACINI, Maria José. (Orgs.). Práticas identitárias: língua e discurso. São Carlos: Claraluz, 2006, p. 45-56.

ORLANDI, Eni Puccinelli. A questão do assujeitamento: um caso de determinação histórica. Comciência. Disponível em: <http://www. comciencia.br/comciencia/handler.php?section=8\&edicao=26\&id=296>. Acesso em: 21 jul. 2009.

ORLANDI, Eni Puccinelli. Análise de Discurso. In: ORLANDI, Eni Puccinelli; LAGAZZI-RODRIGUES, Suzy. (Orgs.). Discurso $e$ textualidade. Campinas: Pontes, 2006, p. 13-31.

ORLANDI, Eni Puccinelli. Análise de Discurso: princípios e procedimentos. 6. ed. Campinas: Pontes, 2005a.

ORLANDI, Eni Puccinelli. Discurso e texto: formulação e circulação dos sentidos. 2. ed. Campinas: Pontes, 2005b.

ORLANDI, Eni Puccinelli. Interpretação: autoria, leitura e efeitos do trabalho simbólico. 4. ed. Campinas: Pontes, 2004.

PÊCHEUX, Michel. Semântica e discurso: uma crítica à afirmação do óbvio. 4. ed. Tradução de Eni P. Orlandi. Campinas: Ed. da UNICAMP, 2009.

PÊCHEUX, Michel. O Discurso: estrutura ou acontecimento. Tradução de Eni P. Orlandi. 4. ed. Campinas: Pontes, 2006.

PÊCHEUX, Michel. Delimitações, inversões, deslocamentos. Caderno de Estudos Linguísticos. Campinas: Unicamp, n. 19, jul./dez., p. 7-24, 1990.

PÊCHEUX, Michel; FUCHS, Catherine. A Propósito da Análise Automática do Discurso: atualização e perspectivas. In: GADET, Françoise; HAK, Tony. (Orgs.). Por uma análise automática do discurso: uma introdução à obra de Michel Pêcheux. Tradução de Bethânia S. Mariani et al. 3. ed. Campinas: Ed. da UNICAMP, 1997, p. 163-252.

REVUZ, Christine. A língua estrangeira entre o desejo de um outro lugar e o risco do exílio. Tradução de Silvana Serrani-Infante. In: SIGNORINI, 
Inês. (Org.). Língua(gem) e Identidade: elementos para uma discussão no campo aplicado. Campinas: Mercado de Letras; São Paulo: Fapesp, 1998, p. 213-230.

SAUSSURE, Ferdinand de. Curso de Linguística Geral. 27. ed. São Paulo: Cultrix, 2006.

SELINKER, L. Interlanguage. IRAL: International Review of Applied Linguistics. v. 10, n. 3, p. 209-232, august, 1972.

SERRANI-INFANTE, Silvana. Formações discursivas e processos identificatórios na aquisição de línguas. DELTA, São Paulo, v. 13, n. 1, p. 63-81, fev. 1997. Disponível em: <http://www.scielo.br/scielo. php?script=sci_arttext\&pid=S0102-44501997000100004>. Acesso em: 15 jan. 2009. 